\title{
EFEITO DO AIB SOBRE O ENRAIZAMENTO E DESENVOLVIMENTO DE ESTACAS DE QUIVI (Actínidia deliciosa)
}

\author{
EFFECT OF IBA ON THE ROOTING AND DEVELOPMENT \\ OF KIWI CUTTINGS (Actinidia deliciosa)
}

\section{Vitor Manfroi ${ }^{1}$ Ana Helena Dias Francisconi ${ }^{2}$ Carlos Iguassu Nogueira Barradas ${ }^{3}$ Eduardo Seibert ${ }^{4}$}

RESUMO

$O$ objetivo do trabalho foi estudar o efeito do ácido 3-indoibiitirico $(A / B)$ no enraizamento e desenvolvimento de estacas semi-lenhosas de quivi, cv. Monte. $O$ experimento foi conduzido na Estação Experimental Agronômica da UFRGS, em Eldorado do Sul, RS, e constou de cinco tratamentos, com cinco repetições, em blocos casualizados. Usou-se 19 sacos/parcela, com duas estacas/saco plástico, plantadas em uma mistura argila: areia.-esterco (l: $l: \quad I): \quad e$ tratadas com AIB nas concentrações de: 2000ppm, 4000ppm, 6000ppm e 5000ppm, além da testemunha (sem AIB). $O A I B$ não influenciou na porcentagem de enraizamento das estacas, mas resultou no aumento linear do peso seco médio das raízes. Houve, da mesma forma, incrementos lineares no comprimento e no peso seco dos brotos, à medida que se elevou a concentração de AIB.

Palavras-chave: ácido 3-indolbutirico. estaquia, propagação vegetativa, sistema radicular.

\section{SUMMARY}

The objective of this experiment was to study the effect of the 3-indolbutiric acid (IBA) on the rooting and development of semi-hardwood cuttings of kiwi, cv. Monty. The experiment was carried out at the Staccatos Experimental Agronomical/UFRGS in Eldorado do Soul. RS, Brazil with five treatments and five repetitions, in completely randomized blocks design. There were 19 bags per pilot with two cuttings per plastic bag grow in a catty: sane manure mixture (1:1:1) and treated by /BA at the concentrations of 2000ppm, 4000ppm, 6000ppm and $5000 p p m$. In addition to the contrail. IBA did not affect the rooting percentage but resulted in a linear increase of the mean root dry weight. Shoot development was not affected by the IBA. Buy there was a tendency for a linear increase of shoot length and dry weight in response to IBA concentrations above 2000 ppm.

Key words: 3-indolbutiric acid, cutting, and root system. Vegelalive propagation.

\section{INTRODUÇÃO}

O quivi, kiwi ou actinídia chinesa (Actínidia deliciosa) é uma frutífera originária das regiões altas do vale do rio Yang-Tzé, na China (WHILLEY \& SARANAH, 1984). Esta espécie da família das Actinidiáceas vem sendo cultivada em várias regiões do mundo, com destaque na Itália e Nova Zelândia, que possuem uma área ao redor de 20.000ha plantados cada, e no Chile, que possui cerca

\footnotetext{
${ }^{1}$ Engenheiro Agrônomo, MsC., Departamento de Tecnologia dos Alimentos, Instituto de Ciência e Tecnologia dos Alimentos, Universidade Federal do Rio Grande do Sul (UFRGS), Av. Bento Gonçalves, 9500, 90540-000, Porto Alegre - RS. Autor para correspondência.

${ }^{2}$ Engenheiro Agrônomo, Doutora.

${ }^{3}$ Engenheiro Agrônomo, Doutor, Professor Titular, Departamento de Horticultura e Silvicultura, Faculdade de Agronomia, UFRGS.

${ }^{4}$ Engenheiro Agrônomo, Mestrando em Fitotecnia, Departamento de Horticultura e Silvicultura, Faculdade de Agronomia, UFRGS.
} 
de 12.000ha (SCHUCK, 1992a). No Brasil a cultura vem despertando interesse crescente, em função do potencial produtivo e do preço alcançado pela fruta, destacando-se os estados meridionais do país, Rio Grande do Sul e Santa Catarina, como os mais promissores para esta cultura.

O quivi é propagado por estaquia, por enxertia de plantas provenientes de sementes, ou por micropropagação. COSTA \& YOUSSEF (1984) comentam que na Itália, e igualmente no restante da Europa, é muito usada a propagação por estacas de um ou dois anos, enquanto que a enxertia é preferida na Nova Zelândia ou Califórnia. No RS a totalidade dos viveiristas adota a enxertia sobre plantas oriundas de sementes como prática preferencial. SCHUCK (1992b) relatou que poderia se usar na estaquia, estacas dormentes, herbáceas ou de raízes. PONCE \& GARDIAZABAL (1983) verificaram, na Nova Zelândia, que não há diferenças funcionais entre sistemas radiculares de plantas propagadas por estacas e plantas enxertadas. Desta forma, pode-se inferir que a estaquia teria como vantagem uma maior homogeneidade de plantas a nível de campo, já que é uma propagação exclusivamente clonal, sem qualquer influência do porta-enxerto, usualmente obtido por semente.

O uso de reguladores de crescimento com função auxínica, constitui-se em valioso auxiliar no enraizamento de estacas de plantas frutíferas, como é o caso do quivi. Dentre os produtos recomendados pela literatura destaca-se o ácido 3-indolbutírico (AIB), pelas suas características de estabilidade em solução hidroalcoólica, e efeitos marcantes sobre diversas espécies. XIU-ZHEN \& MING (1990) obtiveram taxas de enraizamento acima de $80 \%$ com o uso de AIB em quivi.

Como a cultura do quivi está em franca expansão, há uma grande demanda de mudas, que, quando não supridas localmente, acarreta a necessidade de importação, principalmente do Chile, com gastos de divisas. A pesquisa e os viveiristas, necessariamente, devem estudar formas de diminuir esta dependência, e facilitando a obtenção de mudas, talvez, seja possível reduzir custos de implantação.

$\mathrm{O}$ presente trabalho objetivou avaliar o efeito de diferentes concentrações de AIB sobre o enraizamento e desenvolvimento de estacas de quivi, cv. Monty.

\section{MATERIAIS E MÉTODOS}

O experimento foi conduzido no Setor de Horticultura da Estação Experimental Agronômica, da
Faculdade de Agronomia da UFRGS, em Eldorado do Sul, RS. Foram utilizadas estacas de quivi da cv. Monty. As varas que originaram as estacas foram colhidas na propriedade do Sr. Sadao Suzuki, em Ivoti, RS, no dia 09/08/1991, e, de imediato, foram armazenadas em câmara fria com temperatura em tomo de $10^{\circ} \mathrm{C}$. No dia 13/08/91 as estacas foram preparadas e o ensaio foi implantado em 14/08/91. As estacas, em estádio semi-lenhoso, foram preparadas deixando-se 3 a 4 gemas/estaca (20$25 \mathrm{~cm}$ ), cortando-se em bisel na base, perto da gema, e transversalmente na parte superior.

A base das estacas foi imersa por 5 segundos, nas respectivas concentrações do ácido 3indolbutírico (AIB), sacudidas para escorrer o excesso de solução, e colocadas em contato com o fungicida Captan 25 PM. De imediato foram plantadas em sacos plásticos, com dez furos, duas estacas por saco, deixando-se apenas uma gema sem enterrar. Os sacos plásticos foram colocados sob sombrite, em cima de saibro médio, e imediatamente após a estaquia foram regados.

O substrato usado foi constituído pela mistura areia:argila:esterco $(1: 1: 1 ; \mathrm{v} / \mathrm{v})$. Ao longo do experimento foram feitas regas periódicas em função das necessidades das plantas.

$\mathrm{O}$ experimento foi conduzido segundo o delineamento blocos casualizados, com cinco tratamentos e cinco repetições, cada unidade experimental consistindo de 19 sacos, contendo duas estacas/saco. Os tratamentos foram: 1) testemunha (solução hidroalcoólica a 50\%); 2) 2000ppm de AIB; 3) 4000ppm de AIB; 4) 6000ppm de AIB; 5) 8000 ppm de AIB. O AIB foi preparado com solução hidroalcoólica a $50 \%$.

Quatro meses após o plantio, avaliou-se o enraizamento e desenvolvimento das estacas, estudando as variáveis: 1) porcentagem de pega, 2) peso seco médio das raízes, 3) comprimento médio dos brotos, 4) peso seco médio dos brotos.

Os dados foram submetidos à análise de regressão polinomial. Para a análise, os dados de porcentagem de enraizamento foram submetidos a transformação arco seno.

\section{RESULTADOS E DISCUSSÃO}

$\begin{gathered}\text { Pela análise de regressão o ácido 3- } \\ \text { indolbutírico (AIB) não }\end{gathered}$ influenciou
significativamente na porcentagem de estacas
enraizadas de quivi cv. Monty, ainda que as
concentrações mais elevadas de AIB tenham
permitido as maiores taxas. A média geral desta
variável foi de $86,28 \%$ com um coeficiente de

Ciência Rural, v. 27, n. 1, 1997. 
variação de 7,82\%. Este comportamento difere do apresentado por diversas espécies frutíferas, e também, especificamente, no caso de quivi (PONCE \& GARDIAZABAL, 1983; BARTOLINI \& IANNI, 1990; BIASI et al., 1990), já que nestes trabalhos o AIB induziu diferenças significativas. Encontrou-se, no entanto, que a grande maioria das estacas dos tratamentos com AIB que não enraizaram, formaram calos, comportamento não encontrado nas estacas da testemunha, podendo-se inferir, portanto, que algum outro fator, provavelmente a rega deficiente, tenha influído no sentido de não promover o completo desenvolvimento radicular, inibindo o crescimento das raízes.

Sobre o peso seco médio das raízes das estacas enraizadas, percebeu-se que a medida que se elevou as concentrações de AIB foi maior o peso das raízes (Figura 1); estes resultados concordam com aqueles obtidos por BIASI et al. (1990) que demonstram que o uso de AIB, efetívamente, contribui para o aumento do sistema radicular. Detectou-se que as estacas enraizadas no tratamento sem AIB apresentaram um sistema radicular reduzido, o que poderia trazer problemas no desenvolvimento das mudas quando transplantadas. A avaliação foi realizada aos quatro meses, e foi destrutiva, o que não permitiu acompanhar o comportamento das mudas obtidas a campo, onde poder-se-ia determinar melhor o efeito dos tratamentos sobre o vigor, crescimento e desenvolvimento das mesmas.

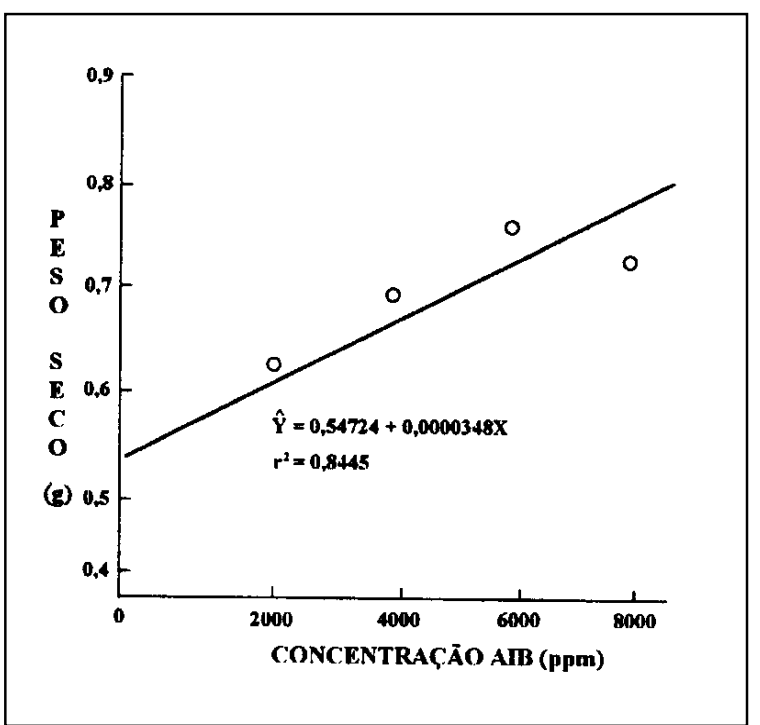

Figura 1 - Efeito de diferentes concentrações de AIB sobre o peso seco médio das raízes de estacas de quivi, cv. Monty. EEA/FA/UFRGS, Eldorado do Sul, RS.
O desenvolvimento vegetativo da parte aérea é apresentado na Figura 2. Para as duas variáveis, comprimento e peso seco médio dos brotos, a análise por regressão indicou um aumento linear, em ambas as variáveis, a medida que se elevou a concentração de AIB. Acredita-se que este seja um comportamento plausível com os dados obtidos quanto ao crescimento do sistema radicular, ainda que o período de quatro meses que as estacas permaneceram no saco plástico até a avaliação, possam ter influído, em parte, para inibir o crescimento dos tratamentos com as doses mais elevadas de AIB.

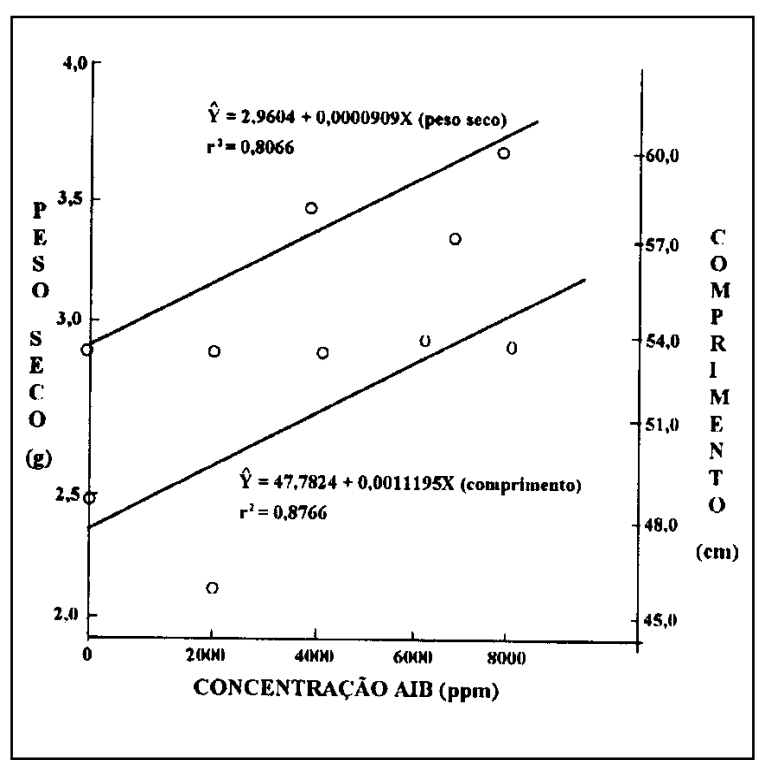

Figura 2 - Efeito de diferentes concentrações de AIB sobre o comprimento de brotos (cm/estaca) e o peso seco dos brotos (g/estaca) de quivi, cv. Monty. EEA/FA/UFRGS. Eldorado do Sul, RS.

\section{CONCLUSÕES}

O AIB não influi na porcentagem de enraizamento das estacas de quivi, cv. Monty, ainda que o fitorregulador tenha favorecido uma maior formação de calos; aumentando a concentração de AIB eleva-se o peso seco médio das raízes das estacas enraizadas e, da mesma forma, o comprimento e peso seco médio dos brotos; o uso de AIB pode ser indicado para viveiristas a fim de melhorar o processo de obtenção de mudas de quivi.

\section{REFERÊNCIAS BIBLIOGRÁFICAS}

BARTOLINI, G., IANNI, G. Kiwi propagation tests with herbaceous and hardwood cuttings. Acta Horticulturae, Hagne, n.282,p.239-41, 1990. 
BIASI, R., MARTNO, G., COSTA, G. Propagation on Hayward Florianópolis, v. 5, n. 4, p. 13-8, 1992b. (Actinidia deliciosa) from soft and semi-hardwood cuttings. Acta Horticulturae, Hagne, n. 282, p. 243-50, 1990, P(NCE. APGARD1AZABAL. F. 1. Propagation dei $\mathrm{km}$ por estacas. Revista Fruticola, Santiago, v. 4, n. 1, p. 17-9, 1983

COSTA, G., IOUSSEF. J. Decisivi progressi per ractinidia. Rivista di Frutticoltura, Milano, v. 50, n. 3, p. 57-60, 1984.

SCHUCK, E. Cultivares de quivi. Agropecuária Catarinense, Florianópolis, v. 5, n. 4., p. 9-12. 1992a.

SCHUCK, E. Propagação do quivi. Agropecuária Catarinense,
Florianópolis, v. 5, n. 4, p. 13-8, 1992 b.

PONCE, A. P., GARDIAZABAL, F. I. Propagation del kiwi por estacas. Revista Frutícola, Santiago, v. 4, n.1, p. 17-9, 1983.

XIU-ZHEN, G., MING, X. A survey of recents studies on Actinidia species in China. Acta Horticulturae, Hagne, n. 282, p. 43-56, 1990.

WHILLEY, W., SARANAH, J. B. Kiwifruit; a new fruit crop for Queensland. Queensland Agricultural Journal, Melbourne, v. 110, n. 3, p. 167-75, 1984. 